\title{
Okul Yöneticilerinin Mizah ve Disiplin Anlayışı
}

DOI: $10.26466 /$ opus.392882

\section{Mustafa Çelikten $^{*}-$ Yeliz Çelikten ${ }^{* *}$}

\author{
*Prof. Dr., Erciyes Üniversitesi, Eğitim Fakültesi, Melikgazi / Kayseri / Türkiye \\ E-Posta: celikten@erciyes.edu.tr ORCID: 0000-0001-7966-3912 \\ **Öğretmen, Kepez İlkokulu, Talas /Kayseri \\ E-Posta: yelizyeni1979@gmail.com ORCID:
}

Öz

Mizah, tarih boyunca felsefe, edebiyat, psikoloji, sosyoloji, eğitim ve yönetim gibi farkl disiplinlerden birçok düşünür, yazar ve araştırmacının ilgisini çekmiş ve üzerinde son ylllarda araştırmaların yo$\breve{g}$ unlaşttğg bir kavramdır. Sosyal bir olgu olan mizah sosyal ilişkilerin önemli bir öğesidir. Okul yöneticilerinin mizah algilamalarında ve kullanabilmelerinde insanlara, olaylara ve özellikle problemlere karşı özgün bakabilmeleri, ilişkilerdeki ironi ve komediyi fark edebilmeleri oldukça önemlidir. Bununla birlikte öğretmenlerin eğitsel düzlemde mizahın kullanımına yönelik tutumlarının olumlu olması da önemlidir. Çünkü eğitsel yaşantıların yön bulmasında öğretmenlerin eğitsel kavramlara dönük tutumlarının oldukça büyük payı bulunmaktadır. Mizah ile ilgili yapılan çağdaş psikolojik araştırmaların hemen hemen hepsi, mizah duygusunun gerek psikolojik gerekse sağllk ve iyilik durumunu geliştiren olumlu ve istenir bir kişilik özelliği olduğu varsayımına dayanmaktadır. Araştırmacılar genellikle yüksek bir mizah duygusuna sahip insanların; iyimserlik, kendini kabul, özgüven ve özerklik gibi olumlu özellikler taşıdıklarını varsaymışlardır. Okul içi iletişimlerde okul yöneticisinin payı yadsınamaz bir gerçektir. Okul yöneticisi olumlu bir tavır sergilediği sürece öğretmen, öğrenci ve velilerin de eğitim-öğretime katılmaya istekli olmaları; dolayısıyla okula karşı olumlu bir tutum benimsemeleri beklenmektedir. Okul yöneticisi tarafindan iletişimde mizahi bir yol izlenmesinin, zorlukları kolaylaştırmak, olumsuzlukları olumluya dönüştürmek için hep birlikte çalışma isteğine neden olacağı düşünülmektedir.

Anahtar Kelimeler: Okul, Sistem, Yönetim, Mizah, Disiplin

OPUS (c) Uluslararası Toplum Araştırmaları Dergisi-International Journal of Society Researches ISSN:2528-9527 E-ISSN : 2528-9535

http://opusjournal.net 


\title{
Humor and Discipline Perception of School Admi- nistrators
}

\begin{abstract}
Humor is a concept that has attracted the attention of many thinkers, writers and researchers from different disciplines such as philosophy, literature, psychology, sociology, education and management throughout history and it has been intensively researched in recent years. Humor, a social phenomenon, is an important factor of social relations. It is very important for school administrators to be able to approach the people, the events and the particularly the problems originally in their humor perception and use, and to realize the ironies in relations and comedy. In addition to this, it is also important that teachers' attitudes towards use of humor on educational level are positive. This is because teachers' attitudes towards educational concepts have a considerable share in determining educational experiences. Almost all of the contemporary psychological researches on humor are based on the assumption that sense of humor is a positive and desired personality trait which develops both state of psychology, health and well-being. Researchers have assumed that people who have a high sense of humor have positive features such as optimism, self-acceptance, self-confidence and autonomy. In inter-school communication, the school manager's role is a stubborn fact. As long as the school manager has a positive attitude, teachers, students and parents are supposed to be willing to participate in education; therefore, they are expected to adopt a positive attitude towards school. It is thought that following a humorous way in communication by the school manager will lead to the desire to work together to ease the difficulties and to turn the negative things into positive.
\end{abstract}

Keywords: School, System, Management, Humor

OPUS (c) Uluslararası Toplum Araştırmaları Dergisi-International Journal of Society Researches ISSN:2528-9527 E-ISSN : 2528-9535

http://opusjournal.net 


\section{Giriş}

Mizah insan yaşamındaki en önemli konulardan biridir. Çünkü mizah ve gülme hayatın oksijeni olarak görülmektedir. Mizah, eğlendirme, güldürme ve bir kimsenin davranışına incitmeden takılma amacını güden ince alay, güldürmece, gerçeğin güldürücü yanlarını ortaya koyan edebiyat türü, ironi (Türk Dil Kurumu, 2005) gibi anlamlara gelmektedir. Oxford İngilizce sözlükte mizah; eğlenceyi, şakacılığı, komikliği harekete geçiren eylemin, konuşmanın ya da yazının niteliğini ifade etmektedir (Martin, 1998). Bu anlamda mizahın temelinde eğlence ve hoşgörü (Balcıŏlu ve Öngören, 1973) bulunmaktadır. Ancak mizah tamamen eğlence olmadığı gibi eğlence de tamamen mizah değildir.

Mizah denildiği zaman akla gelen önemli kavramlar arasında mizah duygusu ve mizah tarzı bulunmaktadır. Mizah duygusu, karmaşık doğası gereği tanımlanması zor bir kavramdır. Bundan dolayı mizah duygusu farklı şekillerde ele alınmaktadır. Martin (2001) mizah duygusunu, "eğlence, kahkaha, şakacılık ve benzeri ile ilgili davranışlar, deneyimler, tutumlar ve yeteneklerin her türlü süreklilik kazanmış bireysel farklılığı" olarak tanımlamaktadır. Raskin'e (1998) göre mizah duygusu, mizahtan hoşlanma, yorum ve anlayış yeteneğidir. Bu anlamda mizah duygusu eğlencenin de ötesinde bir anlam taşımaktadır. Mizah duygusu sürekli bir farkındalık ve uyanıklık halini beraberinde getirmektedir. Bu durum ise mizah duygusuna sahip bireylerin olumlu insan ilişkileri geliştirmesi sonucunu doğurmaktadır.

Özellikle günümüz iş hayatının monoton ve aşırı ciddi yapısı dikkate alındığında mizah ve gülmenin önemi daha iyi anlaşılmaktadır. Mizah toplumdaki bütün kesimler için gereklidir. Özellikle yönetici konumunda bulunanlar için mizah vazgeçilmezdir. Yöneticiler sürekli olarak karar vermek, sorunları çözmek, diğer bireyleri memnun etmek durumundadır ve bu da genellikle stresli ve gergin ortamlar oluşturmaktadır. Bu gerginliklerle baş etmede mizah önemli bir yere sahiptir. Bu anlamda mizah yöneticilerin kullanabileceği en güçlü araçlardan biridir. Mizahın iletişimde önemli bir yeri ve rolünün olduğu açıtır (Özdemir, 2002).

Eğitim örgütlerinde de mizah kullanımının birçok yararı vardır ve bunlar yapılan araştırmalar ile ortaya konulmuştur. Yapılan bazı 
araştırmalar ile sınıf ortamında mizahın olumlu etkileri olduğu belirlenmiştir (Berk, 2000; Berwald, 1992). Clouse ve Spurgeon (1995) mizahın yaratıcılığı destekleyen bir iletişim şekli olduğunu, bu nedenle de sınıfta mizah kullanımının faydalı olduğunu belirtmiştir. Bu anlamda, sınıfta uygun ve yerinde mizah kullanımı, derslerde öğrenme işlemini kolaylaştırmaktadır. Mizah ayrıca sınıfta destekleyici ve olumlu bir öğrenme iklimi de oluşturmaktadır (Kehr vd., 1999). Örgütsel yaşamda mizah bu kadar önemli bir konu olmasına rağmen eğitim örgütlerinde mizah konusunun ihmal edildiği görülmektedir. Bu araştırmalar arasında okul yöneticilerinin kendi mizah tarzlarını değerlendirdikleri herhangi bir araştırmaya ulaşılamamıştır.

\section{Mizah Tarzlarının Kuramsal ve Uygulamalı Olarak Açıklanması}

Mizah, sosyal ortamlarda bireysel ifade tarzı olarak, bireyin kendisinden ya da diğerlerinden kaynaklanabilir. Yazınbilim incelendiğinde mizah tarzlarının "kendini geliştirici", "katılımcı", "kendini yıkıcı" ve "saldırgan" mizah olarak ele alındığı görülmektedir (Traş ve diğ., 2011:718). Mizah konusunda araştırma yapanlar, mizahın güçlü ve olumlu gücünü kullanmak ve daha iyi anlamak için konu üzerinde daha ciddi çalışmaya gereksinim düşünmektedirler. (Recepoğlu, 2008:76). Bir araştırma da (Kantos, 2011:137) mizah anlayışını yöneticilik özellikleri arasında göstermiştir.

Mizahı kullanırken bazı noktalarda hassas olmak gerekir. Çünkü aksi durumda mizah tam tersi bir etki yaparak, bireyde öfke ve kızgınlığa sebep olabilir. Mizahı kullanırken zamanlama, algılama ve içerik kriterlerini göz önünde bulundurmak gerekir. Mizahın uygun bir zamanda kullanılması önemlidir. Çünkü mizahı yapan kişi buna dikkat etmezse ortam gergin bir hale gelip iletişim olumsuz yönde etkilenebilir. Mizahı kullanırken bireyin bunu nasıl algılayacağını önceden tahmin etmek gerekir. Ĕ̆er mizah yapacak olan birey karşısındaki kişinin mizaha yaklaşımı ve tepkisi konusunda hiçbir bilgiye sahip değilse mizahı kullanması uygun olmayabilir. Ayrıca mizahın içeriği de önemlidir. Özellikle alaycı, bireyi küçük düşüren, cinsellik ve etnik kökenle ilgili şakalardan kaçınılmalıdır. 


\section{Olumlu ve Olumsuz Mizah}

Mizah ile ilgili yapılan çağdaş psikolojik araştırmaların hemen hemen hepsi, mizah duygusunun gerek psikolojik gerekse sağlık ve iyilik durumunu geliştiren olumlu ve istenir bir kişilik özelliği olduğu varsayımına dayanmaktadır. Araştırmacılar genellikle yüksek bir mizah duygusuna sahip insanların; iyimserlik, kendini kabul, özgüven ve özerklik gibi olumlu özellikler taşıdıklarını varsaymışlardır. Her ne kadar bazı araştırmacı ve kuramcılar mizahın psikolojik sağlık ve iyilik durumu ile ilgili olarak olumlu etkilerine değinse de kimileri de bunun aksine mizahın bu yöndeki olumsuz etkilerini dile getirmişlerdir (Yerlikaya, 2003).

Son zamanlarda mizah ile ilgili yapılan çalışmalarda daha çok, iyi olma (wellbeing), ve yaşam doyumu (life satisfaction) gibi psikolojik sağlikla ilgili kavramlarla, mizah anlayışının birlikte ele alındığı görülmektedir. Yapılan bu araştırma sonuçlarına göre, pozitif kavramlarla mizahın birbiriyle bağlantılı olduğu görülmektedir. Ayrıca bu çalışmalar, yüksek mizah duygusuna sahip olan bireylerin stresle daha etkin bir biçimde başa çıabildikleri ve diğer bireylerle daha sağlıklı kişilerarası ilişkiler kurabildiklerini göstermektedir.

\section{Mizahın Olumlu Yanları}

Mizah ve onun sonucu olarak ortaya çıkan kahkahanın beden sağlığ üzerindeki olumlu etkisine dair ilk çalışmalar 1979 yılında Norman Counins tarafından yazılan "Anatomy of an Illness" adlı kitap ile başlamıştır. Yakalandığı "Anklosing Spondelitis" adlı ölümcül hastalığ1 yenmesinde "umut, kahkaha, sevgi, inanç" gibi olumlu duyguların önemine dikkat çeken yazar, mizahın insan psikolojisini olumlu etkileyerek bağışıklık sistemini güçlendirmesiyle ilgili araştırmacılara ilham kaynağı olmuştur (Akt: Küçükbayındır, 2003).

Gülmek sadece insana özgü bir reflekstir. Gülmenin işlevi, insanda gerilim sonrası rahatlama sağlamasıdır. Stres hormonlarının üretimini engelleyerek bağışıklık sistemini güçlendirip; mutluluk hormonu endorfini artırarak da ağrıları dindirmektedir. Negatif duygusal durumlar fiziksel ve psikolojik hastalıklara neden olur. Pozitif duyguların bu hastalıkların iyileştirilmesinde kullanılabileceği fikrinden hareketle gülme terapisi 
önemsenmiş ve kullanılmaya başlanmıştır. Gülme terapisi; stres, depresyon ve kanser gibi çağımızın hastalıklarının tedavisinde destek olarak kullanılmaktadır. Mizah, insanların zihinsel ve fiziksel sağlıklarını korumaları ve hastalıkların başa çıkmada etkin bir role sahiptir.

Maslow (1954), kendini gerçekleştirmiş olan bireylerin mizah tarzlarında saldırgan özellikler olmadığını ve bu bireylerin kendilerini üstün gösterecek herhangi bir şeyi veya cinsellik ve saldırganlıkla ilgili olan mizahi materyalleri, komik bulmadıklarını belirtmiştir (akt., Martin, 1998).

Martin, Puhlik-Doris ve arkadaşları (2003), mizahın olumlu ve olumsuz taraflarının olduğunu bundan dolayı çok boyutlu bir kavram olarak ele alınması gerektiğini belirtmişlerdir. Onlara göre, mizahın olumlu türleri katılımcı mizah ve kendini geliştiren mizah tarzlarıdır. Katılımcı mizah (affiliative humor), bireyin kendi gereksinimlerini önemsemezlik etmeden diğer kişiler üzerinde odaklandığı bir mizah tarzıdır. Katılımcı mizah tarzında, birey kendine ve diğer kişilere karşı saygılı bir biçimde kişilerarası ilişkiler ve etkileşimler geliştirir. Bu mizah tarzında ki bireyler, diğerlerini güldürebilmek için gülünç şeyler söyler, başkaları için şakalar yapar, ilişkileri kolaylaştırmaya çalışırlar. Kişilerarası gerilimleri azaltmaya eğilimli bir yapıları vardır (Martin ve diğ., 2003; akt., Yerlikaya, 2003). (Tez-alıntı).

\section{Mizah ve Okul Yönetimi}

Kurum başarısında, belirleyici bir otoriteye sahip olmak, okul yöneticisine ait bazı psikolojik özellikleri de ön plana çıkarır. Yöneticilerin mutlu olması, hayata olumlu bakması, örgüt iklimini de olumlu yönde etkilemektedir. Okul yöneticiliği sorumluluğu ağır bir meslek alanıdır. Öğrencilerimizin çocukluk, ergenlik ve gençlik yıllarının şekillendiği okul yıllarının kalitesinden sorumlu olmak, yöneticide ağır bir yük yaratmaktadır. Öğrencilerimizde, olumsuz yaşanmışlıkların olmaması için okul yöneticilerinin akademik yeterlikleri ile birlikte olumlu mizahi bakış açısına sahip ve yaşam doyumuna ulaşmış olmaları da gerekmektedir.

Eğitim sisteminin yapı ve işleyişindeki aksaklıklar ve yetersizlikler, yetkin okul yöneticilerinin yokluğuyla doğrudan ilişkilidir. Okulun işley- 
işi ve okul yöneticileri üzerinde yapılan araştırmalarda; okul yöneticilerinin, okullarda başarının anahtarı olduğu gözlemlenmiştir (Açıkalın, 1998; Karip ve Köksal, 1999). Okul yöneticilerinin hayata karşı bir nevi duruşları olan mizahi bakış açıları yani mizah tarzları onların yaşamdan aldıkları hazzı da doğrudan etkilemektedir. Yönetimde karşılaşılan sorunların çözümünde, değişimi yönetmede, izleyenleri motive etmede ve etkili liderlik davranışlarının sergilenmesinde mizahın olumlu etkisi araştırmacılar tarafından açık bir şekilde vurgulanmaktadır. Araştırmacılar mizah kuramları çerçevesinde araştırmalarını temellendirmişler ve mizahın doğasını anlamaya ve anlatmaya çalışmışlardır.

Okul yöneticilerinin mizah yönelimleri ile ilgili çalışmalar Philbrick (1989) ile başlamıştır. Bunun yanı sıra okul yöneticilerinin yönetsel eylemleri gerçekleştirirken mizah kullanımlarının öğretmenler olumlu etkilerinin olduğu belirlenmiştir. Okul yöneticilerinin mizah kullanımı ile; okul iklimine (Koonce, 1997), okul kültürüne (Hoy, Tarter and Kottkamp, 1991; Peterson ve Deal, 1998), stresi azaltmaya (Williams ve Clouse, 1991; Chapman ve Foot, 1996) ve iş doyumuna (Barth, 1990; Marlowe, 1995;) olumlu katkı sağladıkları belirlenmiştir. Okul yöneticilerinin mizah kullanımı ile öğretmenlerin örgütsel bağlılıklarını güçlendirdiği (Clouse ve Spurgeon, 1995), örgütsel güven duygularını artırdığı ifade edilmiştir (Goleman, Boyatzis ve McKee, 2002). Bu durum Rizzo, Wanzer ve Booth-Butterfield (1999) tarafından mizahın işgörenler arasında ilişkileri geliştirmesi ve işgörenleri örgütsel amaçlar doğrultusunda motive etmesi şeklinde açiklanmıştır.

Eğitsel bağlamda öğrenmelerin kalıcılığı önemlidir. Ders içeriği veya konuyla ilgili ve kaliteli bir mizah unsurunun kullanılması, bilginin kodlanmasını, yapılandırılmasını, bellekte tutulmasını ve hatırlanmasını kolaylaştıracaktır. Mizah, tekdüzeliği ortadan kaldırarak derslere hareketlilik kazandırır. Bununla birlikte mizahi etkinlikler, konunun mantık sisteminin sorgulanmasını sağlamada, öğrencinin güdülenmesini artırmada, dikkatini ölçmede ve problem davranışlarını ortadan kaldırmada da kullanılabilir (Oral, 2004; Savaş, 2009; Atçı, 2004; İnam, bt). Mizah, sınıf atmosferini yumuşatarak ve olumlu iklim yaratarak elverişli öğrenme ortamları oluşturur (Lei, Cohen ve Russler, 2010; Kırtay, 2012; Jeder, 2015). Tüm bunlarla birlikte öğrenciler, istenen öğretmen özelliklerini 
tanımlarken sıklıkla mizah anlayışının önemine değinmiştirler (Gardner, 2006).

\section{Etkili Okul}

Etkili okulun en temel varsayımlarından biri hiç kuşkusuz öğretmenlerin öğretebileceği ve öğrencilerin öğrenebileceği inancıdır. Bu anlayış olmadan etkililiğe ulaşılamaz. Öyleyse, her yönetici , öğretmen ve öğrenci buna inandıkça ismi ne olursa olsun, imkanlar ne kadar olumsuz görünürse görünsün okullar etkili olacaklardır ( Oral ,2005 : 111 ). Etkili okul, tüm öğrencilerin akademik başarılarının geliştirildiği , özellikle düşük başarı gösteren öğrencilere özel bir ilginin gösterildiği ve öğrencilerin sosyal özgeçmişlerinden bağımsız olarak birlikte uyum içinde bulundukları okuldur. Etkili okulda öğretim yönünden güçlü öğrenciler kadar standartların altındaki öğrenciler de temel becerileri öğrenir ( Kaplan, 2008:8).

Örgütsel değişim ve gelişimi sağlamada özellikle yöneticiler kilit rol oynamalıdır. Liderlik niteliklerine sahip yöneticiler, değişen iç ve dış çevre koşulları karşısında, değişime duyulan ihtiyacın belirlenmesini sağlayabilir, değişim için örgüt üyelerini güdüleyebilir, uygun kişileri görevlendirebilir, paylaşımlı bir vizyon oluşturarak, bireylerin birer değişim ajanı olarak görev yapmasını sağlayabilirler (Özmen ve Sönmez, 2007, 193). Okulda etkili bir yapının oluşturulması için okulun örgütsel yapısının yeniden örgütlendirilmesi (reorganizasyon) yoluna başvurulabilir. Reorganizasyon, örgütsel gelişmeyi başarmak için başvurulacak etkili bir yoldur. Ancak yeniden örgütlenme için belirli şartların oluşması gereklidir. Yeniden örgütlenmeye gitmek için çevrede ve teknolojide belirli değişmelerin gerçekleşmesi, örgütsel büyüme, siyasal değişme, önderlik değişimi gibi zorlayıcı gelişmelerin oluşması gerekir (Erdoğan, 2008, 151).

Okulların gelişen ve kendini sürekli yenileyen ve bu sayede bilgi toplumunda olması gereken yeri alması ve bunun içinde okulların yeniden yapılanması gerekmektedir. Bu yapılanma, bir bakıma, okul kültürünü şekillendiren yönetimden başlamalıdır. Yönetim işbirliği, sorumluluk, destekleme ve güdüleme gibi davranışları temel alarak oluşturacağı kültür doğrultusunda, sürekli öğrenen, gelişen ve performansı yüksek 
okulların oluşmasını sağlar. Bu yönetimsel davranışlar dönüşümcü liderliğin temel aldığı davranışlardır. Bu bakımdan okullarımızın gelişimini sağlamak için okul yönetimlerinde dönüşümcü liderlik davranışlarının uygulanması gerekmektedir (Eryılmaz, 2006:2-3). Okul yöneticilerinin dönüşümcü liderlik yeterliklerine sahip olması, okul örgütünde değişimi, yeniliği, işbirliğini, yüksek performans ve kaliteyi, entelektüel birikimi artırıcı, bir örgütsel kültürün içerisinde oluşmasını sağlayacaktır.

\section{Okul Yöneticilerinin Mizah Tarzlarının Betimlenmesi}

Etkili iletişimin önemli unsurlarından birisi olan mizah, uzun yıllardır üzerinde tartışılan ve çalışılan bir olgudur. Özellikle kişilerarası iletişimin kalitesini artırması açısından önem arz etmesi nedeniyle, daha yoğun çalışmalara ihtiyaç duyulan bir kavramdır. Her alanda olduğu gibi mizahın sosyal bir ortam olarak okullarda kullanımı da kaçınılmazdır.

Sonuç olarak iş yaşamında ortak hedefler doğrultusunda çalışan bireyler belli bir sosyal grubu oluşturmakta, dolayısıyla örgüt iklimi açısından belli bir sinerji üretilmesine olanak sağlayan iletişim ortamları mizah yoluyla etkileşime dönüştürülebilmektedir. Çalışanlar fikirlerini espriler aracılığıyla aktarabildikleri durumlarda, olumsuzluklar etkisini yitirebilir; grup içi çatışmaların azalması sağlanabilir. İş yaşamını paylaşan bireylerin duygularını samimi bir biçimde ifade etmekten kaçındıkları ortamlarda var olan durumu mizahi yolla ortaya koymaya çalışmaları, karşısındakilere kırıcı olma riskini ortadan kaldırabileceği gibi zaman içerisinde bireyler arasında ortak bir mizahi dil gelişimini de sağlayabilir.

\section{Mizahın Okul Ortamına Yansımaları}

Okullar, etkili bir eğitim ve öğretim sağlayabilmek için uygun ve olumlu bir örgüt kültürü oluşturmak zorundadırlar. Okulun dinamikleri doğru zamanda doğru yerde kullanılmalı, tecrübeler paylaşılmalı ve ortak amaçlara doğru ortak hareket edilmelidir. Bir örgüt iklimi insanlar arasında sıcak ve samimi bir ilişkiye olanak sağlıyorsa insanların kişisel özellikleri davranışlarına daha çok yansıyabilir. Esprili bir insan, insanların arasında soğuk ve resmi bir ilişki atmosferi olan bir ortamda bu özelliğini pek yansıtamazken, sıcak ve samimi bir ortamda bu yönünü 
yaşantıya dökebilir. Mizahi yaşantılar geliştirme de bir davranış olarak ele alınırsa bu davranışın niteliğini ve sıklığını, dolayısı ile sonuçları ile ilişkisini, örgüt ikliminin insan ilişkileri boyutunun etkilemesi beklenebilir (Çetin, 2009).

Araştırmalar yönetici becerileri ve örgüt ikliminin, örgütlerde amaçların gerçekleştirilmesi bakımından önemli etkenler olduğunu göstermiştir. Örgüt yöneticilerinin, yönetimde insan ilişkileri yaklaşımını benimsemesi ve başarıyla uygulaması gerekmektedir. İnsan ilişkilerinin yoğun olarak yaşandığ Zira eğitim örgütlerinin girdisi ve çıtısı insan olduğu için bu tür örgütlerde insan ilişkileri daha çok önem kazanmaktadır. Eğitim sistemi içinde yer alan en önemli eğitim örgütleri ise eğitim sisteminin var oluş nedeni olan okullardır (Akar, 2006).

Okul içi iletişimlerde okul yöneticisinin payı yadsınamaz bir gerçektir. Okul yöneticisi olumlu bir tavır sergilediği sürece öğretmen, öğrenci ve velilerin de eğitim-öğretime katılmaya istekli olmaları; dolayısıyla okula karşı olumlu bir tutum benimsemeleri beklenmektedir. Okul yöneticisi tarafından iletişimde mizahi bir yol izlenmesinin, zorlukları kolaylaştırmak, olumsuzlukları olumluya dönüştürmek için hep birlikte çalışma isteğine neden olacağı düşünülmektedir.

\section{Sonuç}

Mizah, tarih boyunca felsefe, edebiyat, psikoloji, sosyoloji, eğitim ve yönetim gibi farklı disiplinlerden birçok düşünür, yazar ve araştırmacının ilgisini çekmiş ve üzerinde son yıllarda araştırmaların yoğunlaştığı bir kavramdır. "Komik", "gülünç", "espritüel”, "esprili", "şakacı", "mizah anlayışına sahip", "mizah duygusuna sahip", "mizah yeteneğine sahip", "muzip" vb. kavramlar günlük yaşantımızda Mizah ve mizah ile sıklıkla ilişkilendirilen kavramlardır. Sosyal bir olgu olan mizah (Martin, 2007) sosyal ilişkilerin önemli bir öğesidir.

Öğretmenlerin eğitsel ortamlarda mizahı algılamalarında ve kullanabilmelerindeki tek olmasa da ön şart, 'mizah arşivine sahip olmaları' ve insanlara, olaylara veya doğaya yaratıc, özgün bakabilmeleri, çevredeki ve ilişkilerdeki ironi ve komediyi fark edebilmeleridir (Oral, 2004; Ivy, 2013). Bununla birlikte öğretmenlerin eğitsel düzlemde mizahın 
kullanımına yönelik tutumlarının olumlu olması da önemlidir. Çünkü eğitsel yaşantıların yön bulmasında öğretmenlerin eğitsel kavramlara dönük tutumlarının oldukça büyük payı bulunmaktadır (Semerci ve Semerci, 2004).

Son zamanlarda mizah ile ilgili yapılan çalışmalarda daha çok, iyi olma (wellbeing), ve yaşam doyumu (life satisfaction) gibi psikolojik sağlıkla ilgili kavramlarla, mizah anlayışının birlikte ele alındığı görülmektedir. Yapılan bu araştırma sonuçlarına göre, pozitif kavramlarla mizahın birbiriyle bağlantılı olduğu görülmektedir. Ayrıca bu çalışmalar, yüksek mizah duygusuna sahip olan bireylerin stresle daha etkin bir biçimde başa çıabildikleri ve diğer bireylerle daha sağlıklı kişilerarası ilişkiler kurabildiklerini göstermektedir.

Eğitim sisteminin yapı ve işleyişindeki aksaklıklar ve yetersizlikler, yetkin okul yöneticilerinin yokluğuyla doğrudan ilişkilidir. Okulun işleyişi ve okul yöneticileri üzerinde yapılan araştırmalarda; okul yöneticilerinin, okullarda başarının anahtarı olduğu gözlemlenmiştir (Açıkalın, 1998; Karip ve Köksal, 1999). Okul yöneticilerinin hayata karşı bir nevi duruşları olan mizahi bakış açıları yani mizah tarzları onların yaşamdan aldıkları hazzı da doğrudan etkilemektedir. Yönetimde karşılaşılan sorunların çözümünde, değişimi yönetmede, izleyenleri motive etmede ve etkili liderlik davranışlarının sergilenmesinde mizahın olumlu etkisi araştırmacılar tarafından açı bir şekilde vurgulanmaktadır. Araştırmacılar mizah kuramları çerçevesinde araştırmalarını temellendirmişler ve mizahın doğasını anlamaya ve anlatmaya çalışmışlardır.

\section{Kaynakça}

Açıalın, A. (1998). Toplumsal, kurumsal teknik yönleriyle okul yöneticiliği. Ankara: Pegem Yayıncilik.

Akar, A. (2006). Illköğretim okullarında öğretmen algılarına göre yöneticilerin, yöneticilik becerilerinin örgüt iklimine katkısı (Ankara ili örneği). Yayımlanmamış yüksek lisans tezi. Gazi Üniversitesi Eğitim Bilimleri Enstitüsü, Ankara. 
Atçı, A. (2004). İlköğretim I. kademe öğretmenlerinin sımı içi problem davranışlara yönelik müdahalelerinin incelenmesi. Yayımlanmamış Yüksek Lisans Tezi, Çukurova Üniversitesi, Adana

Balcioglu, S. ve Öngören, F. (1973). 50 yılın Türk mizah ve karikatürü. İstanbul: Türkiye İş Bankası Yayınları.

Barth, R. S. (1990). A personal vision of a good school. Phi Delta Kappan, 71, 512-516.

Berk, R. A. (2000). Does humor in course tests reduce anxiety and improve performance? College Teaching, 48(4), 151-158.

Berwald, J. P. (1992). Teaching French language and culture by means of humor. French Review, 66 (2), 189-200.

Chapman, A. J. and Foot, H. C. (Eds) (1996). Humor and laughter: theory, research, and applications (New Brunswick, NJ, Transaction).

Clouse, R. W. \& Spurgeon, K. (1995). Corporate analysis of humor. Psychology: A Journal of Human Behavior, 32 (3-4), 1-24.

Çetin, M. (2009). Çalışanlarm mizah tarzlarının işe ilişkin duygusal iyilik algılar üzerine etkisi ve sosyal iklimin bu ilişki üzerindeki şartl değiş̧ken rolü. Yayımlanmamış yüksek lisans tezi, Marmara Üniversitesi Sosyal Bilimler Enstitüsü, İstanbul.

Erdoğan, İ. (2008). Eğitim ve Okul Yönetimi (7. Baskı). İstanbul : Alfa Yayınları.

Eryılmaz, E. (2006). Endüstri meslek lisesi okul müdürlerinin dönüşümcü liderlik özelliklerine sahip olma düzeyleri ( Ankara İli Örneği). Yayımlanmamış Yüksek Lisans Tezi, Gazi Üniversitesi Eğitim Bilimleri Enstitüsü Eğitim Yönetimi ve Denetimi Bilim Dalı, Kütahya.

Gardner, R. L. (2006). Humor in pedagogy: How ha-ha can lead to aha! College Teaching, 54 (1), 177-180.

Goleman, D., Boyatzis, R. and McKee, A. (2002). Primal leadership. Boston, Massachusetts: Harvard Business Press.

Hoy, W. K., Tarter, C. J. ve Kottkamp, R. B. (1991). Open schools/healthy schools: Measuring organizational climate. Newbury Park, CA, Sage.

Ivy, L. L. (2013). Using humor in classroom. Education Digest. 79(2), 54-57.

İnam, A. (bt). Mizah kaynağı olarak eğitim sorunlarına genel bir bakış. http://www.phil.metu.edu.tr/ahmetinam/mizahkaynagi.htm (Erişim tarihi: 19.11.2015) 
Jeder, D. (2015). Implications of using humor in the classroom. ProcediaSocial and Behavioral Sciences, 180, 828-833.

Kantos, Z. E. (2011). Örgüt metaforlarinda liderlik: Kavramsal bir çözümleme. Ĕ̆itim Bilimleri ve Araştırma Dergisi, 1(1):35-158.

Kaplan, F. (2008). Anadolu liselerinin etkili okul özelliklerini karşılama düzeyi (Ankara İli Örneği). Yayınlanmamış Yüksek Lisans Tezi, Gazi Üniversitesi Eğitim Bilimleri Enstitüsü Eğitim Bilimleri Anabilim Dall, Ankara.

Karip, E. ve Köksal, K. (1999). Okul yöneticilerinin yetiştirilmesi. Kuram ve Uygulamada Ĕ̆itim Yönetimi Dergisi, 18, 193-207

Kehr, N., Molstad, S. ve Donahue, R. (1999). Using humor in the college classroom to enhance teaching effectiveness in dread course. College Student Journal, 33 (3), 400-406

Kırtay, O. (2012). Reklam iletilerinde mizah kullanımı: Öğeler, teknikler ve uygulama örnekleri. Yayımlanmamış Doktora Tezi. İstanbul Kültür Üniversitesi, İstanbul.

Koonce, W. J. (1997). The relationship between principals'humor styles and school climate in elementary schools (Doctoral dissertation). Retrieved from ProQuest Dissertations and Theses database. (UMI No. 9731494)

Küçükbayındır, Z. (2003). Mizah eğitiminin iş tatmini ve örgüt iklimine etkisi. Yayınlanmamış yüksek lisans tezi, Marmara Üniversitesi Sosyal Bilimler Enstitüsü, İstanbul.

Lei, S. A. Cohen, J. L. ve Russler, K. M. (2010). Humor on learning in the college classroom: Evaluating benefits and drawbacks from instructors' perspectives. Journal of Instructional Psychology, 37(4), 326-331.

Marlowe, J. (1995). The good, the bad, and the bozos. Executive Educator, 17(9), 24-26.

Martin, R. A. (1998). Approaches to the sense of humor: a historical review. In R. Willibald (Ed.), The sense of humor: explorations of personality characteristic. ss. 15-64. Berlin/New York: Mouton de Gruyter.

Martin, R. A. (2001). Humor, laughter, and physical health: Methodological issues and research findings. Psychological Bulletin, 127, 504519. 
Martin, R. A. (2007). The psychology of humor: An integrative approach. San Diego, CA: Elsevier Academic Press

Oral, G. (2004). Ergenlikte mizah ölçeği. Eğitim ve Bilim, 29(133), 20-27.

Oral , Ş. (2005). İlköğretim okullarının etkili okul kavramı açısından değgrlendirilmesi: Batman ili örneği. Yayınlanmış Yüksek Lisans Tezi, Dicle Üniversitesi Sosyal Bilimler Enstitüsü Eğitim Bilimleri Eğitim Anabilim Dalı, Diyarbakır.

Özdemir, A. (2002). Okul yöneticiliğinde mizahi yaklaşım. Türkiye Sosyal Araştırmalar Dergisi, 6 (3), 49-61.

Özmen , F. Ve Y. Sönmez. (2007). Değişim sürecinde eğitim örgütlerinde değişim ajanlarının rolleri.Fırat Üniversitesi Sosyal Bilimler Dergisi , 17(2), 177-198.

Peterson, K. D. ve Deal, T. E. (1998). How leaders influence the culture of schools. Educational Leadership, 56, 28-30.

Philbrick, K. T. (1989). The use of humor and effective leadership styles (Doctoral dissertation). Retrieved from ProQuest Dissertations and Theses database.

Raskin, V. (1998). The sense of humor and the truth. In R. Willibald (Ed.), The sense of humor: explorations of personality characteristic. ss. 95108. Berlin/New York: Mouton de Gruyter.

Recepoğlu, E. (2008). Okul müdürlerinin mizah yeteneğinin öğretmenlerin iş doyumlarına etkisi. Ĕ̆itim ve Bilim, 33(150), 74-86.

Rizzo, B. J., Wanzer, M. B and Booth-Butterfield, M. (1999). Individual differences in managers" use of humor: Subordinate perceptions of managers" humor. Communication Research Reports, 16(4), 360-369.

Savaş, S. (2009). Illköğretim 7. sınıf Türkçe derslerinde mizah kullanımının öğrenci tutum ve başarısına etkisi. Yayımlanmamış Yüksek Lisans Tezi. Zonguldak Karaelmas Üniversitesi, Zonguldak.

Semerci, N. ve Semerci, Ç. (2004). Türkiye'de öğretmenlik tutumları. Fırat Üniversitesi Sosyal Bilimler Dergisi, 14(1), 137-14

Traş, Z., Arslan, Ç., Taş, A. M. (2011). Öğretmen adaylarInda mizah tarzları, problem çözme ve benlik saygısının incelenmesi. Uluslararasi İnsan Bilimleri Dergisi, 8(2):716-732.

Türk Dil Kurumu (2005). Türkçe sözlük. Ankara: Türk Dil Kurumu Yayını. 
Williams, R. A. ve Clouse, R. W. (1991). Humor as a management technique: Its impact on school culture and climate. Report No. EA 023388 (Nashville, TN, Metropolitan NashvilleDavidson County Schools) (ERIC Document Reproduction Service No. ED 337 866).

Yerlikaya, E. E. (2003). Mizah tarzları ölçeğinin uyarlama çalışması. Yayınlanmamış yüksek lisans tezi, Çukurova Üniversitesi, Sosyal Bilimler Enstitüsü, Adana.

\section{Kaynakça Bilgisi / Citation Information}

Çelikten, M. ve Çelikten, Y. (2018). Okul yöneticilerinin mizah ve disiplin anlayışı. OPUS - Uluslararası Toplum Araştırmaları Dergisi, 8(Gençlik Araştırmaları Özel Sayısı), 453-467. 